\title{
2016 Award for an Exemplary Program or Achievement in a Mathematics Department
}

The DEPARTMENT OF MATHEMATICS AT CALIFORNIA STATE UNIVERSITY AT NORTHRIDGE is the recipient of the 2016 Award for an Exemplary Program or Achievement in a Mathematics Department.

\section{Citation}

The American Mathematical Society is pleased to recognize the Department of Mathematics at California State University at Northridge (CSUN) with the 2016 Award for an Exemplary Program or Achievement in a Mathematics Department. CSUN is being recognized for its program "Preparing Undergraduates through Mentoring towards PhDs" (PUMP). The diversity efforts at all levels of the PUMP program have been truly exemplary.

The PUMP program was created in 2005 by a group of faculty members at CSUN with the aim of increasing access to $\mathrm{PhD}$ programs in the Mathematical Sciences for underrepresented minority students. CSUN is a large Hispanic-serving institution in an ethnically and economically diverse region. Before PUMP, the number of mathematics majors at CSUN was tiny and essentially none continued to PhD programs. While PUMP began as a program at CSUN, it was expanded in 2013 to include $10 \mathrm{Cal}$ State campuses. The program has two main features: a centralized residential summer boot camp and a research experience during the academic year at the students' home institutions (across the 10 participating Cal State campuses). Throughout the program, students are closely mentored. They participate in regional and national conferences, and gain a strong sense of community.

For permission to reprint this article, please contact: reprint-permission@ams.org.

DOI: http://dx.doi.org/10.1090/noti1376
Students tend to enter the program thinking that the only career for math majors is high school teaching. Many have not declared math majors before the program. After the program, most become math majors; they are enthusiastic about mathematics research. As an example, more than 80 percent of PUMP participants from 2013 (who graduated college in 2015) have now started graduate programs in the mathematical sciences. The 2013 cohort included 52 percent women, 54 percent Hispanic, 10 percent African American, and 2 percent Native American students.

This program is a true gem. It offers a model that can be adopted nationwide. The program creates a mathematics research culture that is inviting and inclusive for undergraduates from underrepresented groups. Its impact is enormous. The California State Universities involved in this program should be proud of this achievement and their administrations should capitalize on this success by institutionalizing the program with local support.

For the many ways in which the PUMP program at California State University Northridge has had a large impact on underrepresented groups in the mathematical sciences, we are happy to present the AMS Award for Exemplary Program or Achievement to the Department of Mathematics at California State University at Northridge.

\section{About the Award}

The Award for an Exemplary Program or Achievement in a Mathematics Department was established by the AMS Council in 2004 and was given for the first time in 2006. The purpose is to recognize a department that has distinguished itself by undertaking an unusual or particularly effective program of value to the mathematics community, internally or in relation to the rest of society. Departments of mathematical sciences in North 
America that offer at least a bachelor's degree in mathematical sciences are eligible. Through the generous support of an anonymous donor, the award carries a cash prize of US\$5,000.

The award is presented by the AMS Council acting on the recommendation of a selection committee. For the 2016 award, the members of the selection committee were: Michael Dorff, Eric Grinberg, Aloysius Helminck (Chair), Monica Jackson, and Cesar Silva.

The previous recipients of the award are:

- Harvey Mudd College (2006)

- The University of California, Los Angeles (2007)

- The University of Iowa (2008)

- The University of Nebraska, Lincoln (2009)

- North Carolina State University (2010)

- The Math Center at the University of Arizona (2011)

- Bryn Mawr College (2012)

- The University of Texas at Arlington (2013)

- Williams College (2014)

- Iowa State University (2015).

-Exemplary Program Award Selection Committee
American Mathematical Society
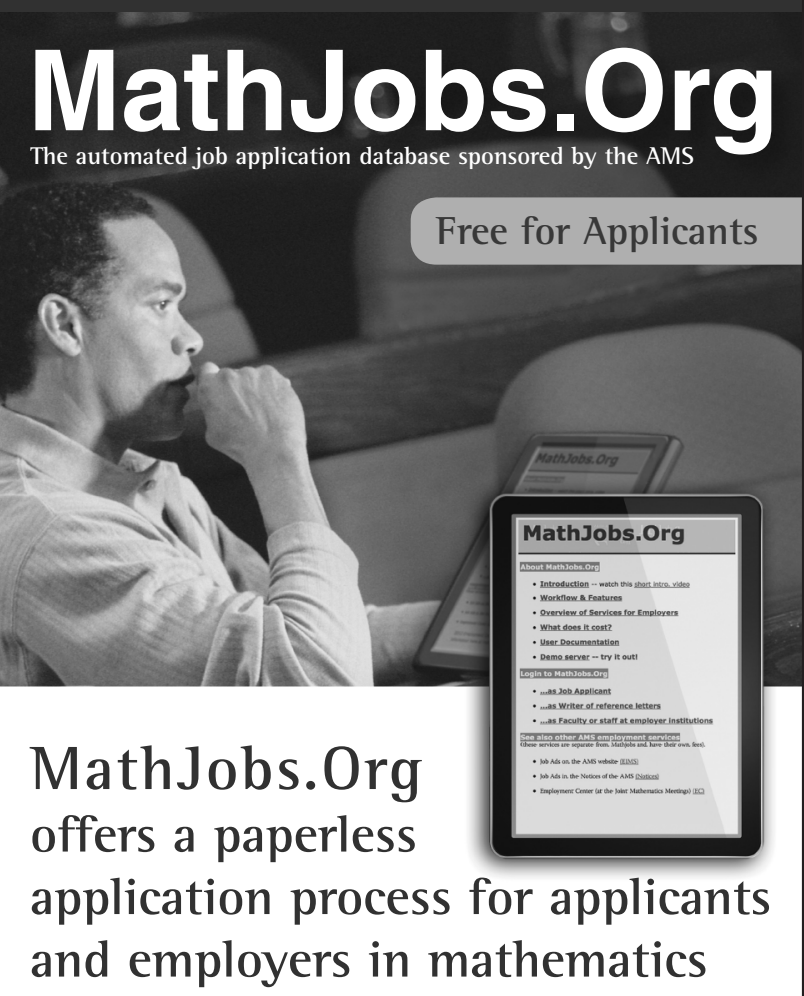

Registered Applicants Can:

- Create their own portfolio of application documents

- Make applications online to participating employers

- Choose to make a cover sheet viewable by all registered employers

\section{Registered Employers Can:}

- Post up to seven job ads

- Set all criteria for required documents, and add specific questions

- Receive and upload reference letters

- Manage applicant information and correspondence quickly and easily

- Set limited access permissions for faculty and EOE administrators

- Search for and sort additional applicants in the database

- Choose an advertising-only account, or a discounted single ad account

Visit mathjobs.org for pricing information

Contact: Membership and Programs Department

American Mathematical Society

201 Charles Street

Providence, RI 02904-2294 USA

800.321.4267, ext. 4105

Email: mathjobs@ams.org

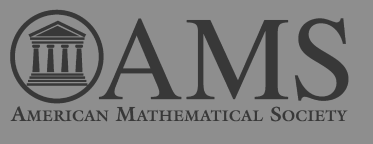

